\title{
Conducting Ethics Research in Prison: Why, Who, and What?
}

\author{
David M. Shaw • Tenzin Wangmo • Bernice S. Elger
}

Received: 8 June 2014 / Accepted: 9 June 2014 / Published online: 5 July 2014

(C) Journal of Bioethical Inquiry Pty Ltd 2014

Why devote an issue of an ethics journal to prison medicine? Why conduct ethics research in prisons in the first place? In this editorial, we explain why prison ethics research is vitally important and illustrate our argument by introducing and briefly discussing the fascinating papers in this special issue of the Journal of Bioethical Inquiry (JBI).

Ethics is often regarded as a theoretical discipline. This is in large part due to ethics' origin as a type of moral philosophy, which is frequently associated with armchair theorising about principles and virtues and seems to have little connection with the "real world." However, medical ethics and bioethics are increasingly becoming empirical disciplines. The "empirical turn" in ethics has led to an explosion in field research in ethics that uses the empirical methods of sociology, anthropology, and the health sciences to investigate a variety of ethical issues. The results of such research are often of much more value than purely theoretical discourses about ethics.

The context of the penal system and incarceration is a particularly fertile field of investigation for empirical ethics. There is a vast literature on the ethics of

D. M. Shaw $\cdot$ T. Wangmo $(\bowtie) \cdot$ B. S. Elger Institute for Biomedical Ethics, University of Basel, Bernoullistrasse 28, CH-4056 Basel, Switzerland e-mail: tenzin.wangmo@unibas.ch

D. M. Shaw

e-mail: david.shaw@unibas.ch

B. S. Elger

e-mail: b.elger@unibas.ch punishment, including detailed dissections of the concepts of retribution, deterrence, and rehabilitation. However, identifying the ethical issues that prisoners and prison staff face (including guards and administrators, but also health care professionals) requires a unique set of approaches to navigate the difficult-to-access prison environment. Immense energy is needed to gain access to the prison setting in order to gather data from prisoners and prison personnel. When conducting research in prison, researchers need to ensure that prisoners are willingly volunteering to participate, without any undue pressure or unrealistic expectations from researchers. Moreover, prison staff grapple on a daily basis with the conflict between the duty to care for prisoners and the duty to protect others. Understanding staff perspectives about the discrepancies they encounter between their professional responsibilities and caring for prisoners can be highly charged, as staff may often find themselves trying to reconcile opposing obligations or fulfilling one obligation at the expense of another. The lived experiences of prisoners and prison staff members and their attitudes towards different ethical issues that challenge them thus must be gathered using face-to-face interviews (and surveys) that employ carefully designed questions to address highly sensitive issues in an indepth but non-threatening manner. As well as providing highly significant data for the field of ethics and prison studies, the results of such research can lead to procedural changes in prison and also enfranchise prisoners by giving them the ability to express their opinions and affect their environment. Through such research, the general public and policy-makers also may come to 
understand the difficult task that prison staff face in fulfilling their duties, particularly in light of restricted resources and growing prison hurdles such as the everincreasing number of prisoners and the ageing of prisoners.

A vast plethora of ethical dilemmas occur in the context of incarceration. In this special issue, a wide spectrum of these topics is explored. Two key issues that are present in many of the papers are the principle of equivalence and dual loyalty. Theoretically, prisoners have a right to receive the same level of health care as that available to people living in the community. In practice, this is more often the exception than the rule, for a variety of reasons. Failure to respect the principle of equivalence can severely affect prisoners' health. Concerns surrounding the lack of equivalence of care for prisoners are discussed in detail in the papers in this issue by Robert L. Trestman (2014) and Wiebke Bretschneider and Bernice Simone Elger (2014).

Dual loyalty arises because of the competing obligations held by health care professionals working in prisons. In addition to the usual responsibilities to their patients, they have a duty to respect the rules of the penitentiary and to protect the public and other prisoners. Dual loyalty can cause great anxiety for doctors and nurses working in prisons, and this dilemma is highlighted in the article by Karolyn L. A. White, Christopher F. C. Jordens, and Ian Kerridge (2014) in this issue.

One of the major problems of ethical inquiry concerning prison medicine, which has not yet been addressed sufficiently, is how health care personnel should react if they find themselves in an unethical environment where the principle of equivalence is not fulfilled and where prison authorities and/or adverse circumstances interfere with the ability of health care personnel to act ethically-for example, if health care personnel are put under pressure to disclose confidential medical information or to disregard the principles of informed consent or informed refusal of treatment. The collection of papers we present does not provide answers to all of the ethical dilemmas that arise in the correctional setting, but we hope it will stimulate further discussion.

Trestman's paper, the first paper in this special issue, offers a comprehensive review of the key ethical issues in prison psychiatry, many of which are also relevant to other areas of caring for prisoners. In addition to the principle of equivalence, he identifies several problematic topics that affect prison psychiatry. These include constraints on privacy, restrictions on patient autonomy, and a general lack of evidence regarding the best strategies for psychiatric care of prisoners. He also discusses the ironic paradox that successful provision of psychiatric care might worsen the penal consequences for patients, indicating the particular complexity of dual loyalty in the context of forensic psychiatry.

Focusing on the responses of 40 experts from three European countries, Bretschneider and Elger explore whether ageing prisoners are in fact receiving equivalent care. Their paper reveals different practical challenges that experts face in respecting the principle of equivalence in prison medicine. They identify four main factors that are particularly problematic and which inhibit access to health care for older prisoners: (a) the variability of care in different prisons; (b) the gatekeeper systems that exist in prisons and result in delayed as well as inadequate access to health care; (c) too few personnel to meet the demands of prisoners; and (d) delays in providing access to health care. This paper is particularly significant as it represents the first empirical study concerning stakeholders' views on the principle of equivalence, which is the standard of health care that prisoners should receive.

Another paper in this issue delves into the perspectives of prison health care staff working in two female prisons in Australia. In their paper, White, Jordens, and Kerridge eloquently present how the prison environment affects the role of health care practitioners. The authors conclude that this unique context "profoundly shape [s] and challenge[s] the ethical and professional obligations" of health care workers with regard to their patients, indicating the pressures that can affect those working in prisons (White, Jordens, and Kerridge 2014, para. 1 under "Discussion"). This research also indicates the importance of using sociological and anthropological methods to inform the design of bioethical studies.

Tenzin Wangmo, Violet Handtke, and Bernice Simone Elger (2014) also tap into the perspectives of stakeholders in their study of mental health practitioners working in Swiss prisons. Wangmo, Handtke, and Elger examine the ethical dilemmas mental health professionals may face when their prisoner-patients mention crimes of which the judicial system may not be aware. Disclosure of past crimes raises several questions: Is this disclosure still relevant? Does anyone stand to be harmed or could someone be saved because of this disclosure? It also raises several concerns, particularly the dilemma these health care providers must confront 
when weighing their duty of patient confidentiality against the need to protect others, if harm to a third party is evident. The study's results indicate that practitioners consider three main factors when considering whether to report crimes to the authorities: whether the prisonerpatient's mental health treatment was voluntary or compulsory, the nature and seriousness of the disclosed crime, and the overall danger posed by the patient. The authors conclude that "legal and ethical requirements concerning confidentiality breaches must be made clear and known to physicians in order to guide them with difficult cases" (Wangmo, Handtke, and Elger 2014, under "Abstract").

Ronald Aday and Lori Farney's paper looks at problematic aspects of health care provision for a specific group of prisoners: elderly women. Their analyses of health data from several hundred incarcerated older women in the southern United States identify high rates of chronic disease, mental illness, and victimization, revealing "the contradictions, dilemmas, and obstacles" facing these women (2014, under "Abstract"). They conclude that age- and gender-sensitive strategies are necessary to provide adequate care for this vulnerable group of prisoners and that such approaches may also yield long-term cost reduction for resource-poor institutions.

Another paper brings forth the point of view of ageing prisoners by addressing their concerns related to death and dying in prison. Arguing for the need to foster autonomy and remove barriers to liberty, Violet Handtke and Tenzin Wangmo examine the concerns ageing prisoners have about end-of-life issues. Key themes include "general thoughts about death and dying, accounts of other prisoners' deaths, availability of end-of-life services, contact with social relations, and wishes to die outside of prison" (2014, under "Abstract"). Handtke and Wangmo conclude that Switzerland faces particular challenges because prisons are organised at a cantonal rather than a federal level and that the issue of requests for assisted suicide in prison should be addressed.

The last paper in this special issue is from Géraldine Ruiz and colleagues (2014), who highlight inconsistencies in the understanding of what "death in custody" means. They report their findings on this controversial issue from the perspectives of experts, mostly lawyers and forensic doctors. In their paper, they reveal that participants felt that categorising deaths in custody in terms of the place of death was problematic and that any definition should emphasise "the link between the detention environment and occurrence of death rather than the actual place of death" (Ruiz et al. 204, para. 1 under "Place of Death," emphasis original). Ultimately, the authors conclude that systematic identification of violence is necessary in order to protect prisoners and prevent deaths in custody and that a comprehensive definition of death in custody is urgently needed.

Additionally, many of the papers in this issue highlight the stresses that the prison environment puts on individual health, access to health care, and end-of-life concerns. Recognising the impact that the prison environment has on the health of prisoners is critical, particularly when deficiencies in the prison system result in prisoner deaths.

Taken together, these papers emphasise the importance of conducting ethics research with prisoners and prison staff. Those incarcerated and those working in prison settings may not be ethicists, but they have their own sense of right and wrong (as well as exposure to professional and religious codes of conduct and practice). It is vital to explore these individuals' views on the prison environment, how they function within the limitations of this environment, and their justifications for the various attitudes that they hold. By conducting research in prisons, ethicists and experts from other disciplines can shed light on ethical and unethical prison practices and, in turn, identify best practices. These findings can thus inform policy changes and improve the circumstances of both prisoners and prison staff. It is only through close ethical examination and analysis that particularly challenging issues such as respecting the principle of equivalence and striking the right balances between dual loyalties can be resolved.

As Guest Editors of this special issue of the $J B I$, it has been an honour to see these papers from a variety of international jurisdictions develop with the assistance of our helpful reviewers and diligent authors. Collectively, this research indicates the immense importance of conducting empirical ethics research in prisons. We hope the collection of papers in this issue highlights the importance of ethics research and prison medicine for a wider audience. 


\section{References}

Aday, R., and L. Farney. 2014. Malign neglect: Assessing older women's health care experiences in prison. Journal of Bioethical Inquiry 11(3). doi:10.1007/s11673-014-9561-0.

Bretschneider, W., and B.S. Elger. 2014. Expert perspectives on Western European prison health services: Do ageing prisoners receive equivalent care? Journal of Bioethical Inquiry 11(3). doi:10.1007/s11673-014-9547-y.

Handtke, V., and T. Wangmo. 2014. Ageing prisoners' views on death and dying: Contemplating end-of-life in prison. Journal of Bioethical Inquiry 11(3). doi:10.1007/s11673-014-9548-x.

Ruiz, G., T. Wangmo, P. Mutzenberg, J. Sinclair, and B.S. Elger. 2014. Understanding death in custody: A case for a comprehensive definition. Journal of Bioethical Inquiry 11(3). doi:10.1007/s11673-014-9545-0.

Trestman, R.L. 2014. Ethics, the law, and prisoners: Protecting society, changing human behavior, and protecting human rights. Journal of Bioethical Inquiry 11(3). doi:10.1007/s11673-014-9560-1.

Wangmo, T., V. Handtke, and B.S. Elger. 2014. Disclosure of past crimes: An analysis of mental health professionals' attitudes towards breaching confidentiality. Journal of Bioethical Inquiry 11(3). doi:10.1007/s11673-014-9546-z.

White, K.L.A., C.F.C. Jordens, and I. Kerridge. 2014. Contextualising professional ethics: The impact of the prison context on the practices and norms of health care practitioners. Journal of Bioethical Inquiry 11(3). doi:10.1007/ s11673-014-9558-8. 